\title{
The Effect of Formaldehyde Vapour on the Lungs of Rabbits
}

\author{
Ochei Kingsley Chinedum ${ }^{1}$, Omeh Yusuf Ndukaku², Obeagu Emmanuel \\ Ifeanyi ${ }^{3}$ and Obarezi Thompson Ndubuisi ${ }^{4}$ \\ 1. Department of Medical Laboratory Sciences, Faculty of Basic Medicine, Ambrose Ali \\ University Ekpoma, Edo State, Nigeria. \\ 2.Department of Biochemistry, Michael Okpara University of Agriculture, Umudike, Abia State, Nigeria. \\ 3. Diagnostic Laboratory Unit, University Health Services Department, Michael Okpara University of \\ Agriculture, Umudike, Abia State, Nigeria. \\ 4.Medical Doctor, University Health Services Department, Michael Okpara University of Agriculture, Umudike \\ Abia State, Nigeria.
}

\begin{abstract}
Formaldehyde is an organic compound with the formula $\mathrm{CH}_{2} \mathrm{O}$ and it is the simplest aldehyde, with systematic name methanol. The aim of this investigation was to sensitize embalming laboratory users of the impending danger associated with overexposure to forty percent (40\%) formaldehyde vapour (the active component of embalming fluid) on the lungs. Twenty adult male albino rats were used for this investigation. The animals were divided into five $(A, B, C, D$, and $E)$ groups. Animals in group $B, C, D$ and $E$ were respectively exposed to forty percent (40\%) formaldehyde for ten(10), fifteen(15), twenty(20) and twenty five(25) days while animals in group A which serve as control group were not exposed to forty percent $(40 \%)$ formaldehyde at all. At different stages of the experiment, the animals in each of the group were decapacitated and the thoracic cage cut open to expose the lungs. The lung tissue was processed for light microscopic investigation adopting the Haematoxylin and Eosin (H and E) staining procedure. The histopathological observation in this study showed that exposure to forty percent (40\%) formaldehyde induced changes in the histology of the lungs. The observed changes were duration dependent. So forty percent (40\%) formaldehyde may be able to have greater marked effect at a prolonged exposure. These findings suggests that forty percent (40\%) formaldehyde vapour may be remarkably toxic on the rat lung tissue and advocate for precautionary measure for human handlers while handling this chemical especially in the histopathology unit for fixation and embalming purposes.
\end{abstract}

Keywords: Embalming, Histopathological, Haematoxylin and Eosin.

\section{Introduction}

Embalming is the process of disinfecting, preserving and restoring a deceased human body to a more lifelike appearance and this process modifies tissue constituents in such a way that the tissue architecture will be retained (Metcalf et al., 1991). However, there are different ways of carrying out embalmment but the most common is the adoption of chemical Solutions and this was first practiced by the Americans by the use of chemical arterial embalming as early as 1980's (Günther, et al., 2002). The most commonly used chemical solution is formalin and the active chemical of choice in most of the embalming laboratories is formaldehyde with the embalming fluid being prepared by mixing some percentage of formaldehyde with different other chemicals (Weast, 1981). Moreover, the mixture formula of this fluid varies depending on the laboratory and some other factors such as the size of organ, oedema and stage of decomposition (Weast, 1981). Though, formaldehyde is also been utilized by chemical industries such as those involved in manufacturing of resins, paper, pharmaceuticals, leather goods, and other products (ANICNA 2007). Interestingly, formaldehyde is water soluble and as such readily absorbed through the lungs and gastrointestinal tracts and to a much lower extent through the skin (Cary and Sullivan 1992). Formaldehyde is an organic compound with the formula $\mathrm{CH} 2 \mathrm{O}$ and it is the simplest aldehyde, with systematic name methanol. Formaldehyde is a colourless gas with a characteristic pungent odour with important precursor to many other chemical compounds, especially for polymers. In 2005, annual world production of formaldehyde was estimated to be 23 million tonnes (50 billion pounds) (Günther, et al. 2002). Commercial solutions of formaldehyde in water, commonly called formalin, were formerly used as disinfectants and for preservation of biological specimens. Formaldehyde is more complicated than many simple carbon compounds because it adopts different forms. Formaldehyde is a gas at room temperature, but the gas readily converts to a variety of derivatives, which are often used in industry in place of the gas. When dissolved in water, formaldehyde combines with water to form methanediol or methylene glycol $\mathrm{H}_{2} \mathrm{C}(\mathrm{OH})_{2}$. The diol also exists in equilibrium with a series of oligomers (short polymers), depending on the concentration and temperature. 


\section{AIMS AND OBJECTIVES}

This work is aimed at sensitizing embalmers of the impending danger that may occur when overexposed to $40 \%$ formaldehyde which constitute the bulk of all the embalming fluids bearing it in mind the health implication that can emanate from laboratory chemicals.

This investigation is therefore aimed at creating awareness to embalming laboratories and by extension to other chemical industries who hardly do without the use of formaldehyde of the impending danger of prolonged exposure, thus reducing the health risk associated with formaldeh

\section{SIGNIFICANCE OF STUDY}

In view of its widespread use, toxicity and volatility, exposure to formaldehyde is a significant consideration for human health.

\section{Animals}

\section{Material And Methods}

Twenty adult male albino rats weighing 60-200g were fed with standard pellet diet (vital feeds produced by Grand cereals limited Km1 7, Zawan round about, Jos, Plateau State, Nigeria) and were provided with clean water. Animals were housed under a controlled room temperature of about $25-28^{\circ} \mathrm{C}$ and photoperiodicity of $12 \mathrm{~h}$ day $/ 12 \mathrm{~h}$ night. All animals were treated in accordance with the guide for the care and use of Laboratory Animals prepared (Ochei and Kolhatkar 2000).

\section{Experimental design}

The animals were assigned into five groups (A, B , C , D , and E) with group A serving as the control group and groups B-E serving as the experimental groups. The control group (group A ; $=4$ ) were not exposed to fourty $(40 \%)$ formaldehyde at all. The exposure of the treated animals was done by soaking cotton wool in formaldehyde ( $40 \%$ formaldehyde at room temperature) and placed in an enclose (designed) wire gauze within the animal cage, thus exposing the animals to the vapour. Animals in group B $(n=4)$ were exposed for ten (10) days to forty $(40 \%)$ formaldehyde vapour. In another group (group $\mathrm{C} ; \mathrm{n}=4)$ the rats were exposed for fifteen (15) days to forty $(40 \%)$ formaldehyde vapour. Animals in group $\mathrm{D}(\mathrm{n}=4)$ were exposed for twenty (20)days to fourty $40 \%$ formaldehyde vapour while those in group $\mathrm{E}(\mathrm{n}=4)$ were given the same treatment for twenty-five $(25)$ days. All animals were fed with pellitisized diet and clean water throughout the experimental period. The animals were de-capacitated at the expiration of the treatment for each of the groups. Subsequently, the thoracic cage was cut open and the lungs excised.

The tissues were fixed with $10 \%$ formal saline and owing to the fact that the lungs were floating, the container was plugged with cotton wool so as to immerse the whole of the lung in the fixative.

$\begin{array}{ll}\mathbf{1 0} \% \text { normal saline } & \\ \mathrm{NaCl} & 9 \mathrm{~g} \\ 40 \% \text { formaldehyde } & 10 \mathrm{ml} \\ \text { Distilled water } & 90 \mathrm{ml}\end{array}$

And it was then processed to light microscopic investigation.

\section{TISSUE PROCESSING AND SECTIONING}

The tissues were processed using processing schedule. The fixed plastic cassette tissues in $10 \%$ formalin were automatically processed by passing them through different grades of alcohol as follows:

$\begin{array}{ll}70 \% \text { alcohol } & 2 \mathrm{hrs} \\ 80 \% \text { alcohol } & 2 \mathrm{hrs} \\ 90 \% \text { alcohol } & 2 \mathrm{hrs} \\ 90 \% \text { alcohol } & 2 \mathrm{hrs} \\ 95 \% \text { alcohol } & 2 \mathrm{hrs} \\ \text { Absolute } & 2 \mathrm{hrs} \\ \text { Xylene 1 } & 2 \mathrm{hrs} \\ \text { Xylene II } & 2 \mathrm{hrs}\end{array}$

Molten paraffin wax $1 \quad 2 \mathrm{hrs}$

Molten paraffin Wax II $2 \mathrm{hrs}$

After the last timing, the tissues were removed from their plastic cassettes and placed at the centre of the metallic tissue mould and then filled with molten paraffin wax. They were also left to solidify after which they were now placed in the refrigerator at $5^{\circ} \mathrm{C}$ for 15 minutes. After the blocks were cool in the refrigerator for the time stated above (15 minutes), the blocks were then removed from the metallic case using a knife and after 
which the paraffin wax at the side of the blocks were removed.

The blocks were then trimmed and cut serially at $3 \mu \mathrm{m}$ on a rotary microtome. The sections were floated in water bath at $55^{\circ} \mathrm{C}$ and picked up by the use of a clean frosted end slides. The frosted end slides were now placed on the hot plate for 40 minutes for adequate attachment of the sections on the slides after which the sections were de-waxed, hydrated, air dried and stored in a slide box ready for staining process.

The lung tissue sections for general tissue structure were stained by Haematoxylin plus Eosin technique.

1. The sections were dewaxed in 3 changes of xylene 5 minutes

2. The sections were hydrated through descending grades of alcohol (absolute, $95 \%, 80 \%$ and $70 \%$ ).

3. The sections were stained in Harris haematoxylin5 minutes

4. The sections were rinsed in running tap-water to remove excess stain

5. The sections were differentiated in $1 \%$ acid alcohol 3 seconds

6. The sections were blued in running tap water 10 minutes

7. The sections were counterstained with $1 \%$ eosin 1 minute

8. Sections were finally rinsed in water, dehydrated in ascending grades of alcohol $(70 \%, 80,95 \%$ and absolute)

9. The sections were cleared in xylene, air-dried and mounted with dibuthylphthalate propylene xylene (DPX). The slides were examined under a light microscope and photomicrographs were taken.

\section{Results}

It was observed that the rats were having eye irritation and they became aggressive on the first three to four days of exposure and also their fur changes from white to yellow as exposure goes on. Eye and nose irritation were also observed including nasal secretion. After about nine to ten days the aggressiveness reduced.

\section{Histological Findings Group}

A: Control

Plates 1-3 below, shows micrographs from control lung sections with normal pulmonary cytoarchitecture.

Micrographs obtained from the control lung sections showed normal pulmonary cytoarchitecture as presented by plates $1 \mathrm{a}-1 \mathrm{c}$.

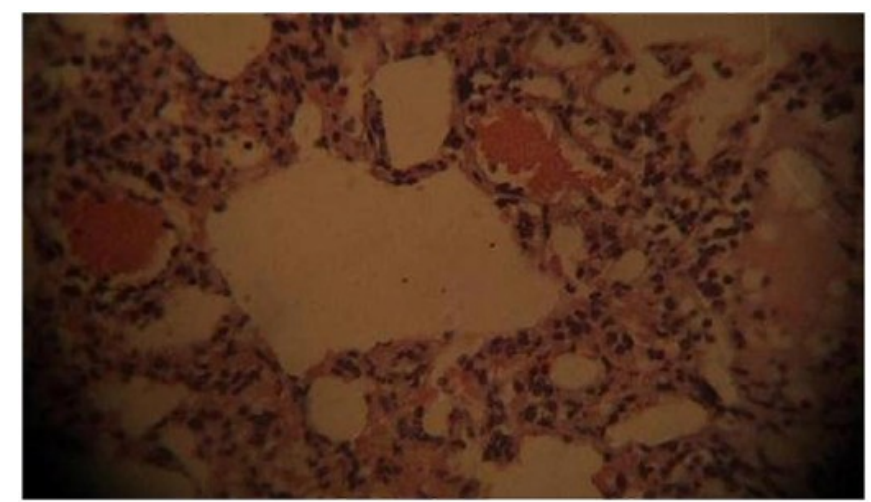

Plate 1a: Lung section $(\mathrm{H}+\mathrm{E} X \mathrm{X} 400)$ showing normal picture.

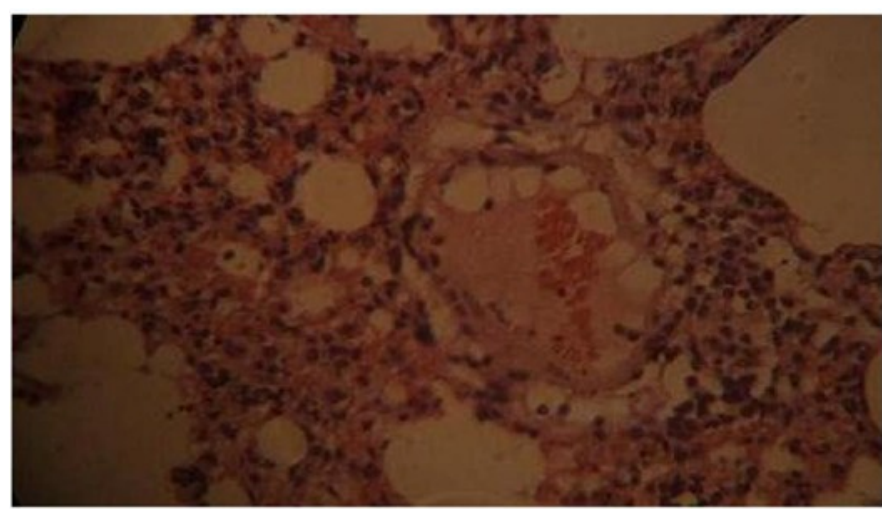

Plate 1b: Lung section ( $\mathrm{H}+\mathrm{E}$ X 400) showing normal picture. 


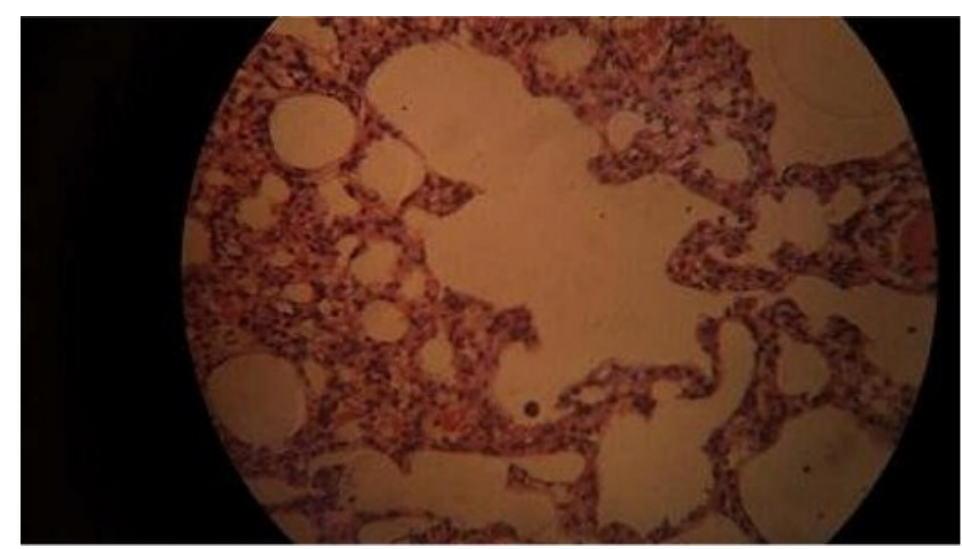

Plate 1c: Lung section $(\mathrm{H}+\mathrm{E} X \mathrm{X} 400)$ showing normal picture.

\section{Group B: test}

Micrographs obtained from the group B test rats (10 days ) lung sections showed distortions in pulmonary cytoarchitecture which includes alveolar wall disruptions, alveolar hemorrhage/Edema, inflammatory cell infiltration, foamy macrophages accumulation, bronchiolar epithelia degeneration, pulmonary fibrosis with thickened alveolar walls, enlarged alveolar walls and type II pneumocytes hyperplasia.

\section{Summary:}

Acute Interstitial Inflammation (Pneumonitis)

Pulmonary fibrosis

Acute Lung Injury

Micrographs obtained from the test B lung sections showed changes in pulmonary cytoarchitecture as presented by plates $2 \mathrm{a}-2 \mathrm{~d}$.

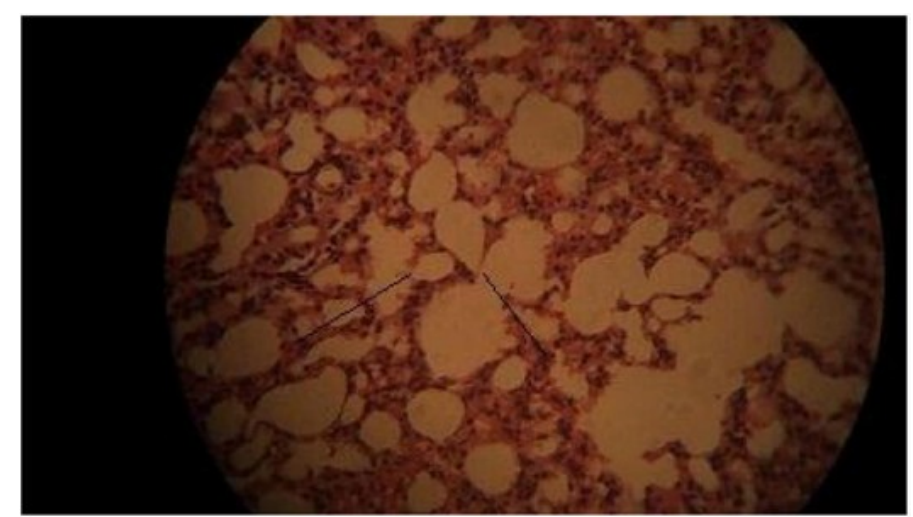

Plate 2a: Lung section (H + E X 400) showing alveolar wall disruptions.

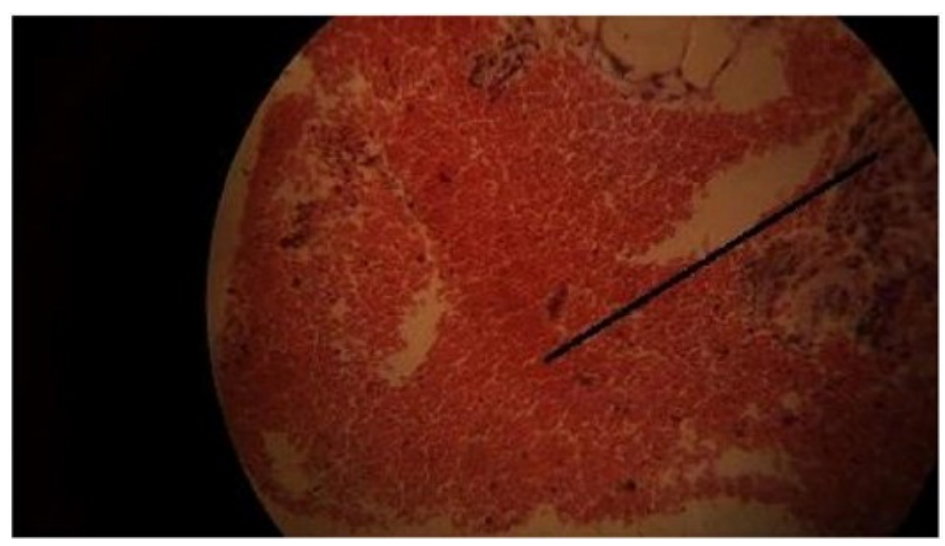

Plate 2b: Lung section (H + E X 400) showing alveolar haemorrhage/Edema. 


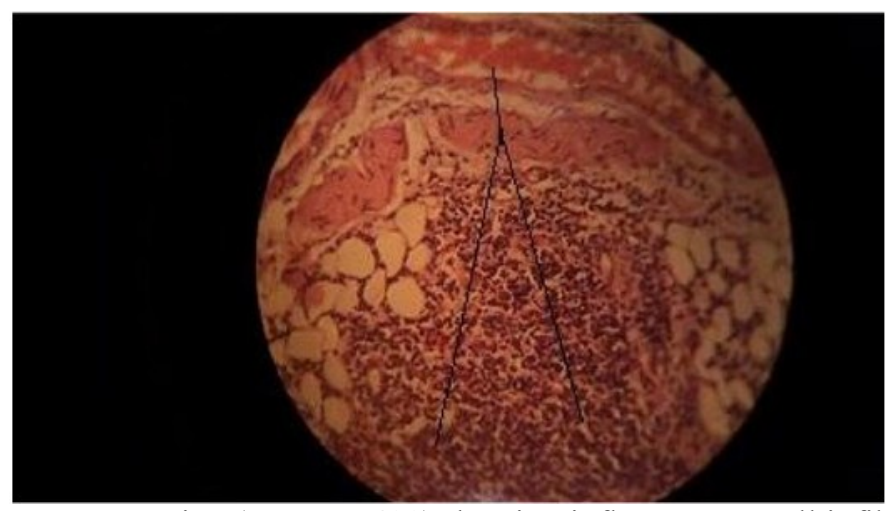

Plate 2c: Lung section $(\mathrm{H}+\mathrm{E} \mathrm{X} \mathrm{400)} \mathrm{showing} \mathrm{inflammatory} \mathrm{cell} \mathrm{infiltration.}$

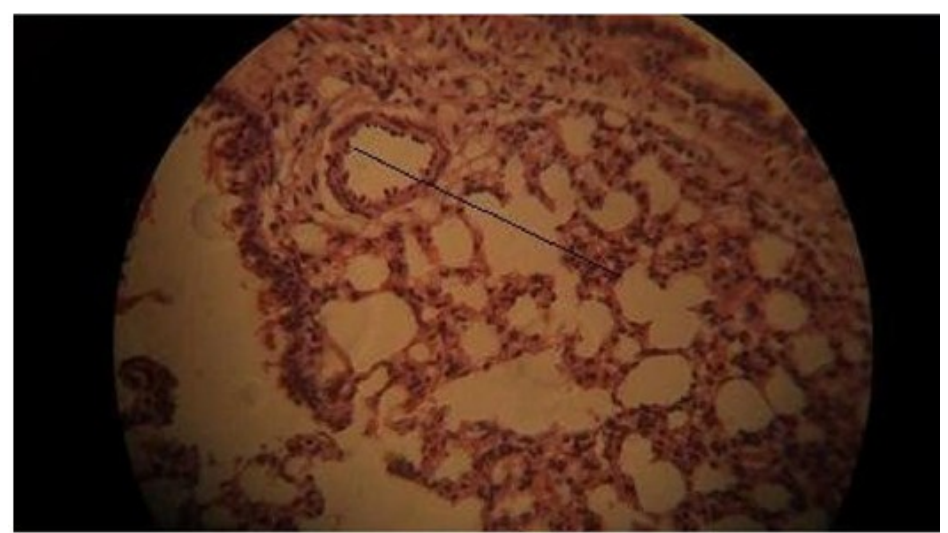

Plate 2d: Lung section (H + E X 400) showing bronchiolar epithelia degeneration

\section{Group C: test}

Micrographs obtained from the group C test rats (15 days ) lung sections showed prominent foamy macrophages accumulation, presence of purulent exudates in the bronchioles, alveolar wall disruptions, alveolar hemorrhage/Edema, inflammatory cell infiltration, hyaline membrane formation, bronchiolar epithelia degeneration, pulmonary fibrosis with thickened alveolar walls, enlarged alveolar walls and type II pneumocytes hyperplasia.

\section{Summary:}

Acute Purulent bronchitis

Acute lung injury

Micrographs obtained from the test $\mathrm{C}$ lung sections showed changes in pulmonary cytoarchitecture as presented by plates $3 \mathrm{a}-3 \mathrm{~d}$. degeneration

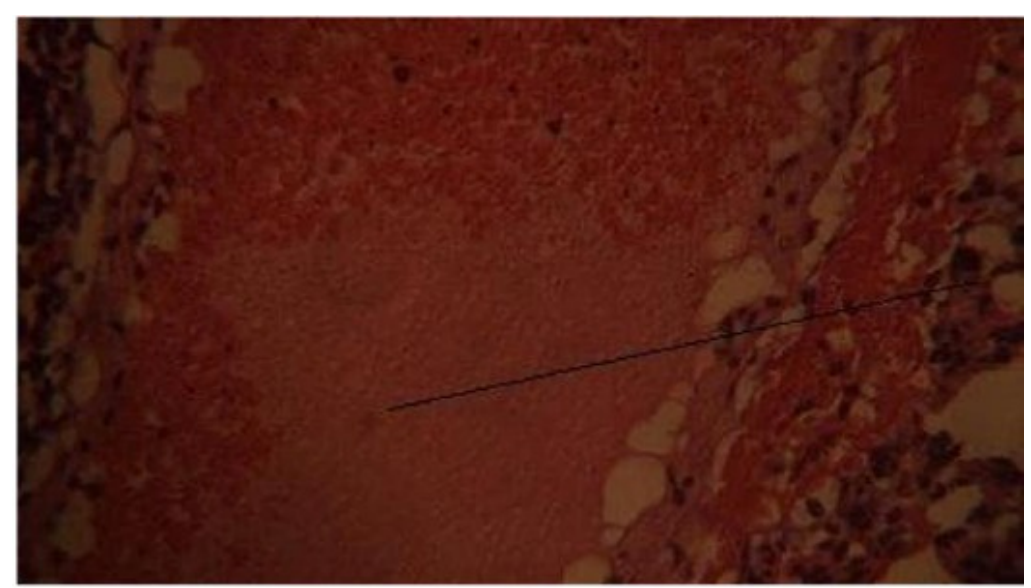

Plate 3a: Lung section ( $\mathrm{H}+\mathrm{E} X \mathrm{X} 400)$ showing presence of purulent exudates in the bronchioles 


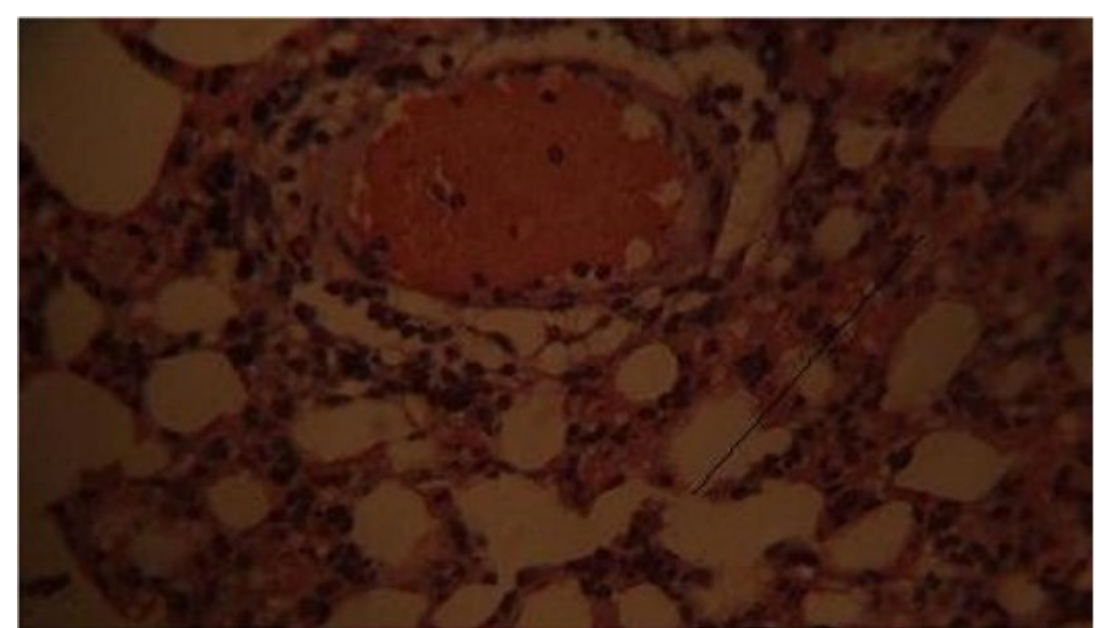

Plate 3b: Lung section ( $\mathrm{H}+\mathrm{E} X \mathrm{X} 400)$ showing alveolar wall disruptions

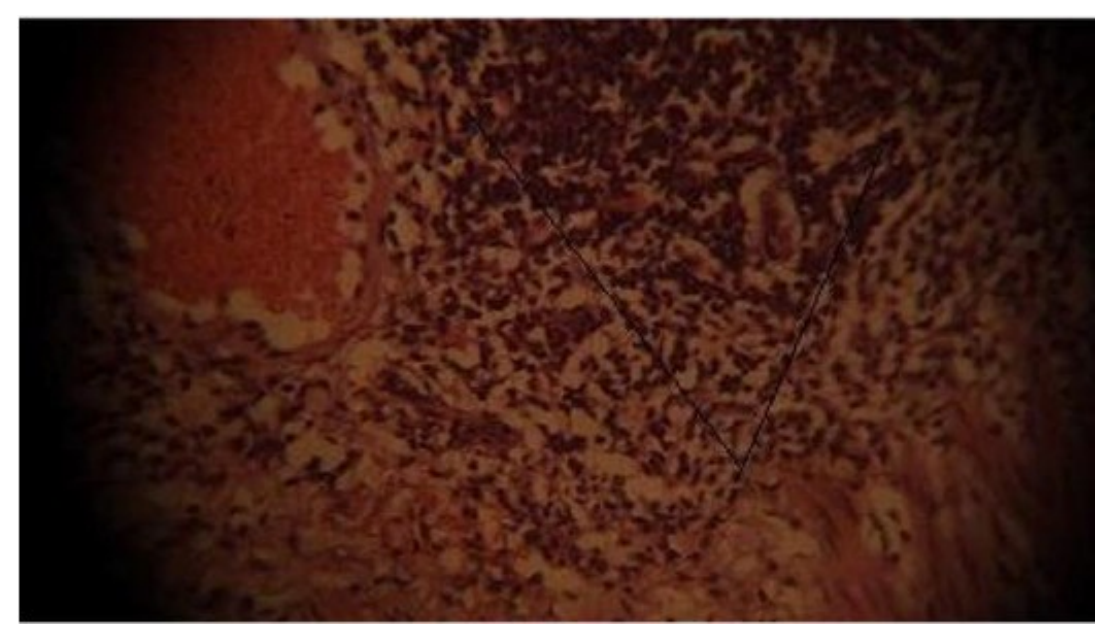

Plate 3c: Lung section (H + E X 400) showing inflammatory cell infiltration

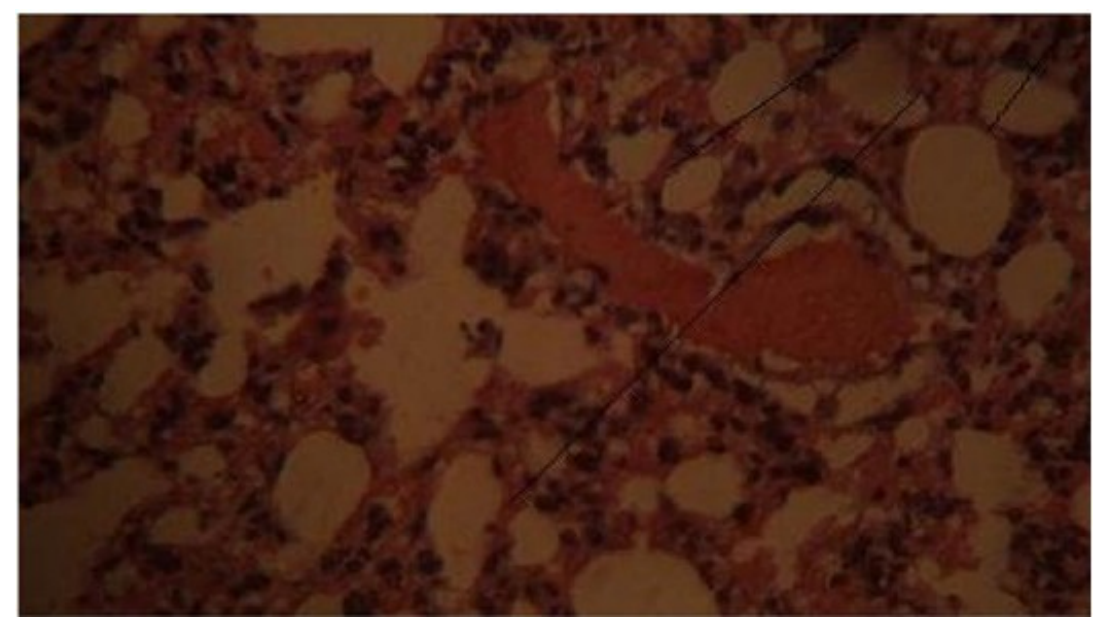

Plate 3d: Lung section ( $\mathrm{H}+\mathrm{E} X \mathrm{X} 400)$ showing hyaline membrane formation

\section{Group D: test}

Micrographs obtained from the group D test rats (20 days ) lung sections showed prominent foamy macrophages accumulation, presence of purulent exudates in the bronchioles, alveolar wall disruptions, alveolar hemorrhage/Edema, inflammatory cell infiltration, cellular pyknosis, hyaline membrane formation, bronchiolar epithelia degeneration, pulmonary fibrosis with thickened alveolar walls, enlarged alveolar walls and Type II pneumocytes hyperplasia.

\section{Summary:}


Chronic Lung Injury

Micrographs obtained from the test D lung sections showed changes in pulmonary cytoarchitecture as presented by plates $4 \mathrm{a}-4 \mathrm{~d}$.

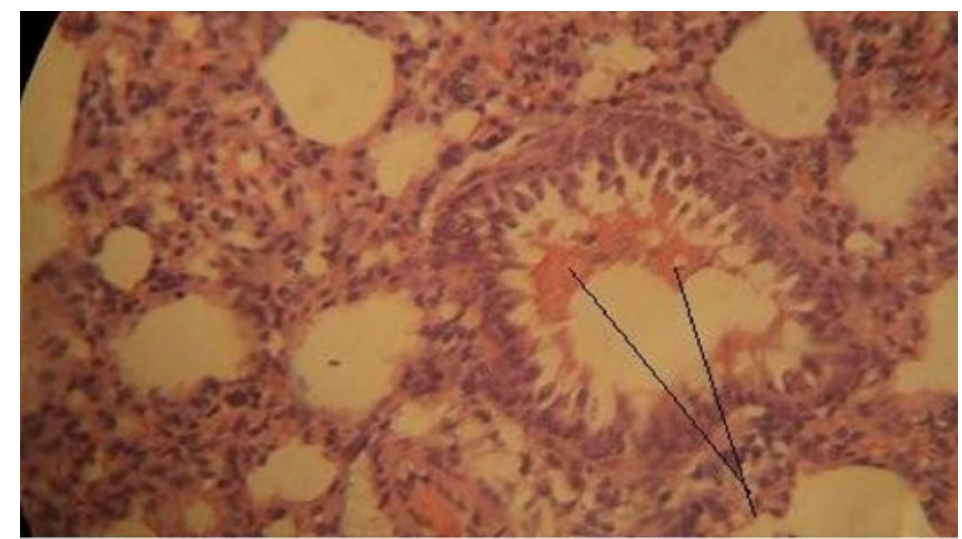

Plate 4a: Lung section (H + E X 400) showing presence of purulent exudates on the bronchiole.
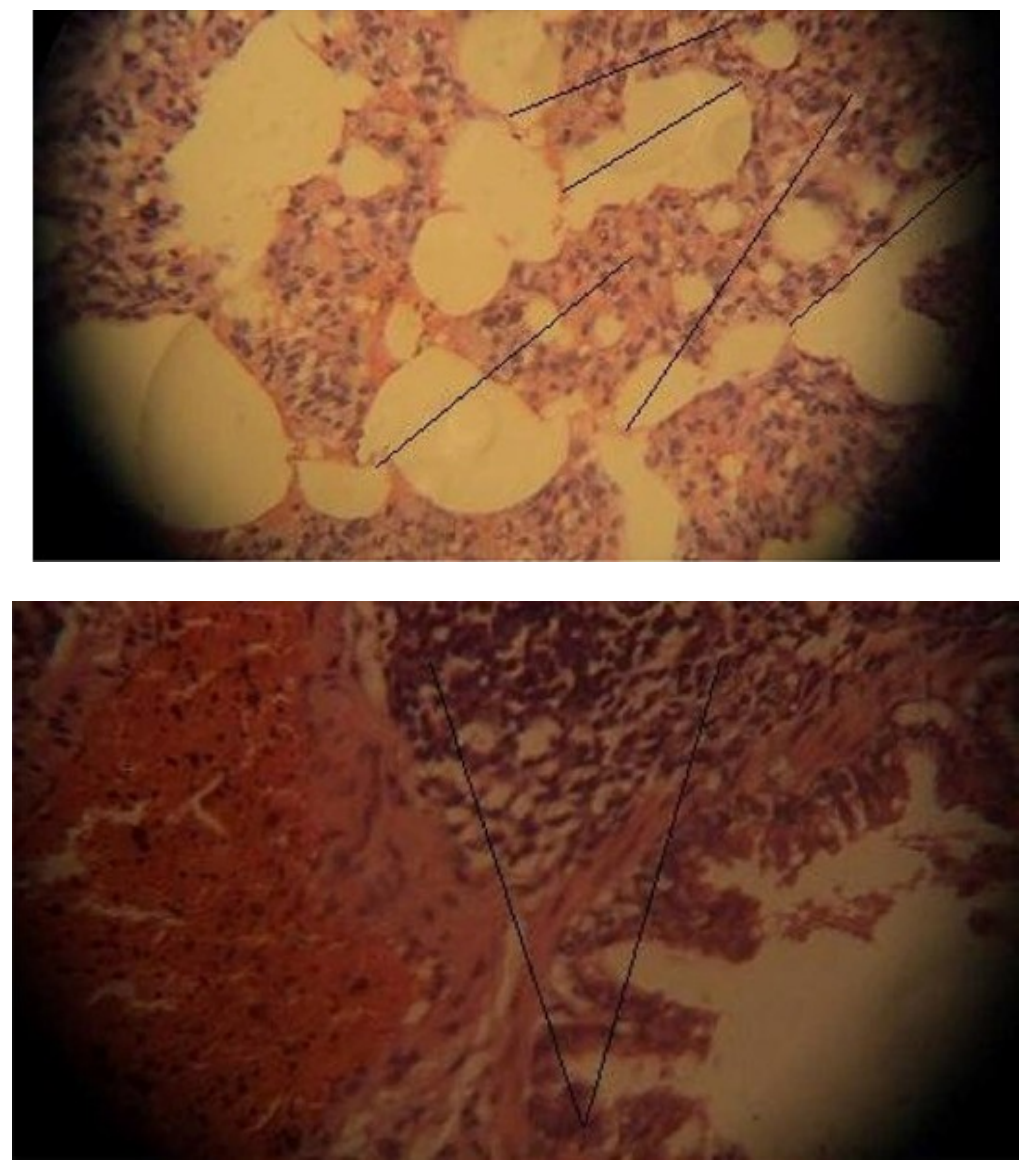

Plate 4c: Lung section $(\mathrm{H}+\mathrm{E} X \mathrm{X} 400)$ showing inflammatory cell infiltration 


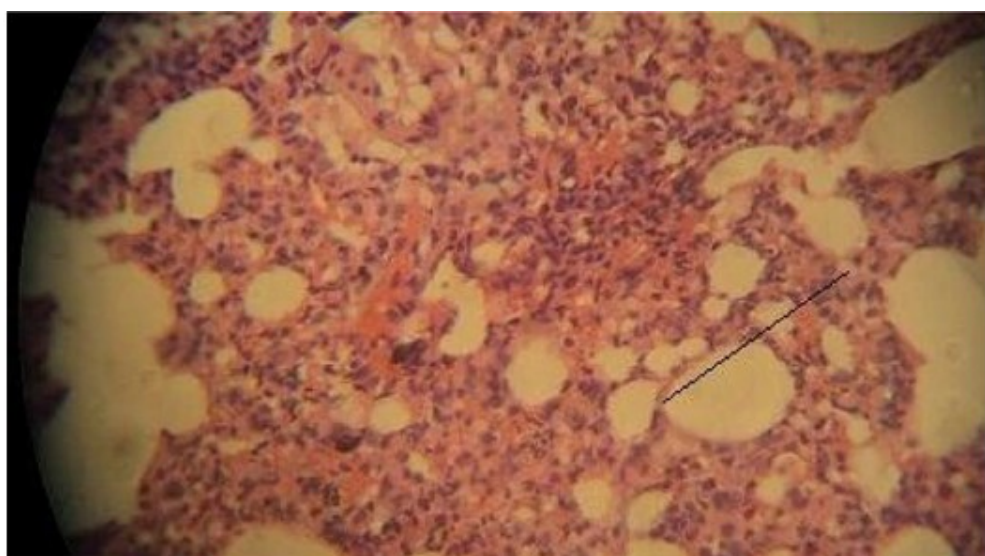

Plate 4d: Lung section (H + E X 400) showing hyaline membrane formation

\section{Group E:test}

Micrographs obtained from the group E test rats (25 days ) lung sections showed prominent foamy macrophages accumulation, presence of purulent exudates in the bronchioles, alveolar wall disruptions, alveolar hemorrhage/Edema, inflammatory cell infiltration, cellular pyknosis, hyaline membrane formation, bronchiolar epithelia degeneration, pulmonary fibrosis with thickened alveolar walls, enlarged alveolar walls and type II pneumocytes hyperplasia.

\section{Summary:}

Chronic Lung Injury

Micrographs obtained from the test $\mathrm{E}$ lung sections showed changes in pulmonary cytoarchitecture as presented by plates $5 \mathrm{a}-5 \mathrm{c}$.

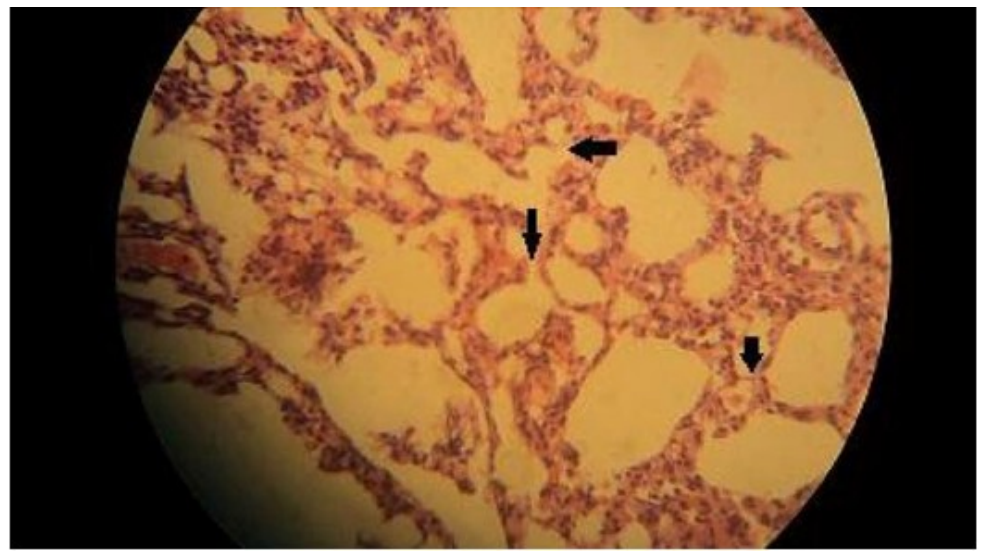

Plate 5a: Lung section ( $\mathrm{H}+\mathrm{E} X$ 400) showing alveolar wall disruptions

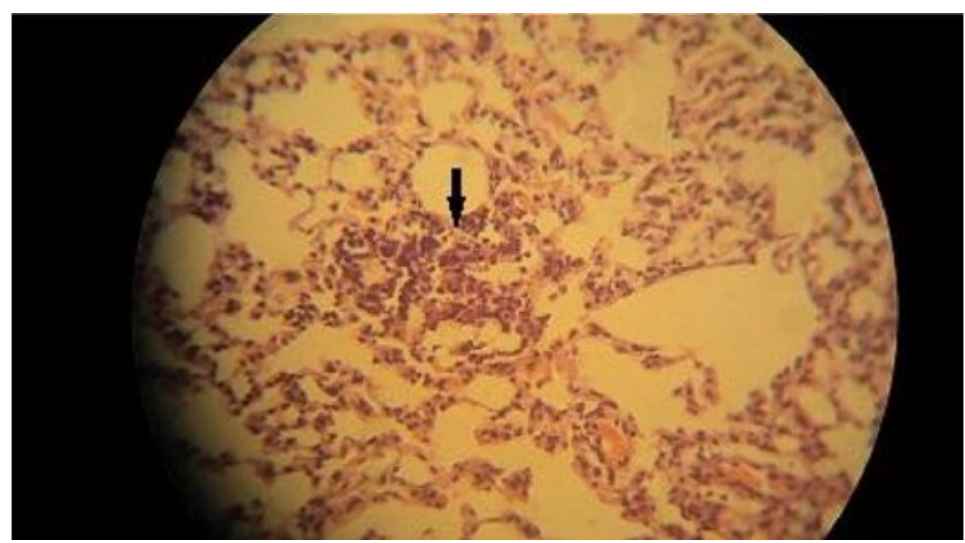

Plate 5b: Lung section ( $\mathrm{H}+\mathrm{E} X \mathrm{X} 400)$ showing inflammatory cell infiltration 


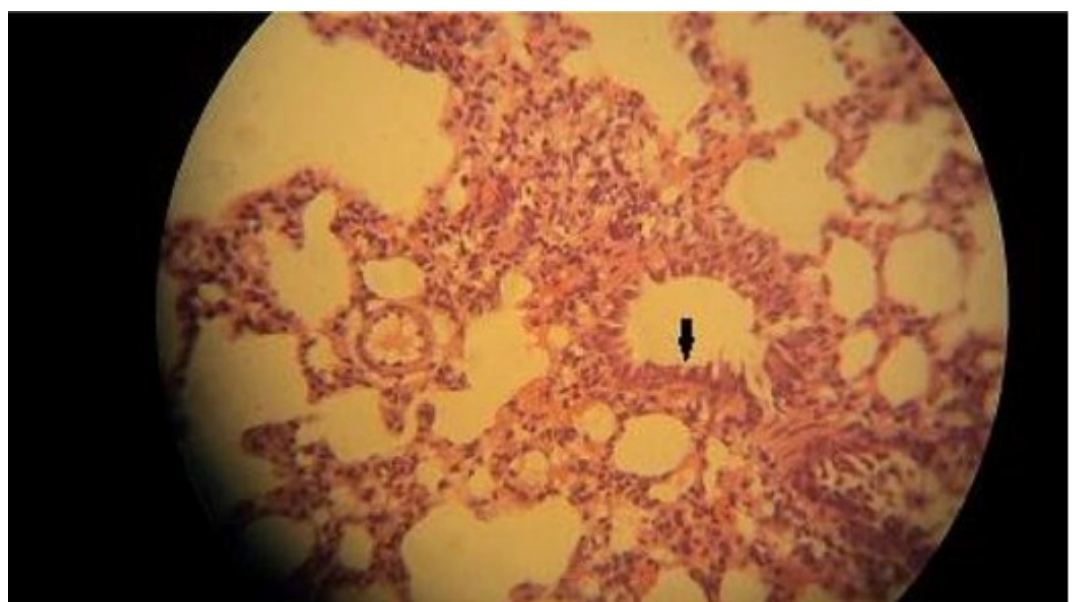

Plate 5c: Lung section $(\mathrm{H}+\mathrm{E} X \mathrm{X} 400)$ showing bronchiolar epithelia degeneration

\section{General Comment}

Exposure to formalin induced changes in the histology of the lungs. The observed changes were duration dependent.

\section{Discussion}

The observed dose-duration dependent changes in the cytoarchitecture of the lungs suggest that formaldehyde is toxic to the pulmonary cells. On the other hand, the observed histological alterations in the pulmonary epithelium ranged from acute interstitial inflammation (pnuemonitis), pulmonary fibrosis, acute purulent bronchitis, acute lung injury and chronic lung injury; similar to that reported by Kamta et al (1996). Similarly, the studies of Woutersen et al. (1989) revealed nasal lesions of respiratory epithelium and yellowing of the fur. The lesions consisted rhinitis squamous metaplasia and basal cell/psuedoepithelial hyperplasia which is in agreement with the observations revealed in my studies which include yellowing of the fur and also nasal lesions in the respiratory epithelium. Rusch et al (1983) showed squamous metaplasia and basal cell metaplasia in the nasal epithelia of rats exposed to formaldehyde which also tarries with the lesions and metaplasia observed in my study. A multispecies study by Salem and Cullumbine reported that formaldehyde exposure resulted in delayed lethality which do not agree with the result of my findings which showed damages to the lungs tissue which I believe will hasten the death of the exposed animals.

In small human studies, exposure to formaldehyde has resulted in eye and upper respiratory tract irritation (Weber- tschopp et al., 1977; Kulle et al., 1987) which was also observed in the eye and the upper respiratory tract of the animals in my study. The eye irritation was confirmed by the presence of tears (watery eyes) in the eyes of the exposed animals and also presence of nasal secretions in the nostrils of the exposed animals confirmed upper respiratory tract irritation.

\section{Conclusion}

The result of the light microscopic investigation of the effect of formaldehyde vapour on the lungs suggests that the formaldehyde is highly toxic at fourty percent (40\%). This toxicity is highly pronounced in animals exposed to fourty percent (40\%) formaldehyde vapour for higher number of days. The histopathological observation in this study showed a great deal of alteration in the cytoarchitecture of the epithelium of the lungs of the treated animals. These alterations may affect the functional capacity of the lungs. The mechanism by which forty percent (40\%) formaldehyde brought about the ulceration of alveoli was by excarvation of the surface epithelium andsupporting tissues of the alveoli wall. The type II pneumocytes so destroyed with the other epithelial cells in the lungs of the treated animals will diminish the secretion of surfactant which reduces surface tension within the alveoli preventing alveolar collapse during respiration. This will in turn, reduce the easy flow of air from the terminal bronchioles in to the alveoli thus reducing the alveoli ventilation. Furthermore, owing to the yellowing of the fur by formaldehyde vapour permit me to say that formaldehyde vapour might have an effect on the skin.

\section{Recommendation}

The histopathological examinations of the lungs of rats inhaling fourty percent (40\%) formaldehyde has shown that formaldehyde being one of the active chemicals in the embalming fluid and in some chemical industries is highly toxic and detrimental to human health. This has further corroborated other investigations. I therefore advocate that more effort should be geared at replacing formaldehyde with less toxic chemical and 
also sensitize embalming laboratory users to be cautious of the impending danger associated with formaldehyde vapour. It is also been recommend that formaldehyde users should wear protective clothing and nose mask when handling this chemical.

\section{References}

[1]. Alexandersson, R., Hedenstierna, G. and Kolmodin-Hedman B., (1982): Exposure to formaldehyde:effects on pulmonary function. Arch Environ Health. 37(5): 279-84.

[2]. American Conference of Governmental Industrial Hygienists (1992): Formaldehyde Application Occupation Environmental Hygene, ISSN: 10960929, 7: 852-874.

[3]. Australian National Industrial Chemicals Notification and Assessment Scheme,2007Formaldehyde in Clothing and Other Textiles, Existing $\mathrm{Ch}$ e mi cals In for mation $\mathrm{S}$ heet,

[4]. http://www.nicnas.gov.au/Publications/Information Sheets/Existin hemical_Information_Sheets/EC_I S_Formaldehyde_1 02007_P DF.pdf, retrieved 2009-09-01

[5]. ATSD R. (1999): Toxicological profile for formaldehyde. Atlanta, GA: Agency forToxic Substances and Disease Registry http://www.atsdr.cdc.gov/ toxprofiles/tp111.pdf.

[6]. Butlerow, A. (1859): "Ueber einige Derivate des Jodmethylens" (On some derivatives of methylene iodide), Annalen der Chemie und Pharmaciel 111 (2); Pp. 242 - 252.

[7]. Cary, J.J. and Sullivan, J.B. Jr., (1992): Formaldehyde In Hazardous Material Toxicology, Williams and Williams's publisher, Baltimore.

[8]. Cotes, J.F. (1994): Lung function, $4^{\text {th }}$ Edition, st Louis Mosby, Pp. 1508. Campaign for Safe Cosmetics, (2009): No More Toxic Tub: Getting

[9]. \&RCtDP aCDCts 2 ut 2 fiKaedLeC'T BD1K 113 1L1RCDe IDLe 3 LROOs,

[10]. http://safecosmetics.org/downloads/NoMoreToxicTub Mar09Report. pdf.

[11]. Dallas, C.E., Badeaux P, Theiss JC and Fairchild EJ (1989).The influence of Inhaled formaldehyde on rat lung cytochrome P450. Environ Res 49(1):50-9.

[12]. Dales, R., Liu, L., Wheeler, A.J., Gilbert, N.L. (2008): Quality of indoor Residential air and health. Canadian Medical Association Journal (Canadian Medical Association Journal) 179 (2) (2): 147-52.

[13]. Dapson, J.N . and Dapson, R.W. (1999) : Hazardous Material in The Histopathology Laboratory: Regulation, Risks, Handling and Disposal, $3^{\text {rd }}$ edition AnatecLimited, Battle Creek, pp 255.

[14]. De Groot, Anton C., Flyvholm, Mari-Ann, Lensen, Gerda, Menné, Torkil, Coenraads, Pieter-Jan (2009): Formaldehyde-releasers: relationship toformaldehyde contact allergy. Contact allergy to formaldehyde and inventory of formaldehyde-releasers, Contact Dermatitis. 61 (2): 63-85.

[15]. ESIS, European Chemical Substances Information System (2009): European

[16]. Commission Joint Research Centre Institute for Health and

[17]. Consume Protection,

[18]. http://ecb.jrc.ec.europa.eu/esis/

[19]. Evans, Ben (2008): FEMA limits formaldehyde in trailers, Boston.com,

[20]. http://www.boston.com/news/nation/washington/articles/2008/ 04/1 1/fema_limits_formaldehyde_in_trailers/, retrieved 2008-0904.

[21]. Formaldehyde and Indoor Air, Health Canada,( 2005): ISBN 0815511299

[22]. http://www.hc-sc.gc.ca/iyh-vsv/environ/formaldehyde e.html, retrieved2009-09-01.

[23]. Formaldehyde Epidemiology, Toxicology and Environmental Group. August (2002): Accessed on April 25, 2010.

[24]. Formaldehyde in China. (2009): Production, Consumption, Exposure Levels, and Health Effect. Environmental International, 35 (8); Pp. 1210-1224.

[25]. Formaldehyde in Clothing and Other Textiles (2007): Existing Chemicals Information Sheet, Australian National Industrial

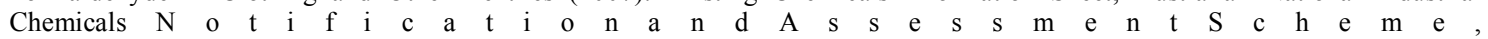
http://www.nicnas.gov.au/Publications/Information Sheets/Existing Chemical_Information_Sheets/EC_IS_Formaldehyde_1 02007 PD F.pdf, retrieved 2009-09-01.

[26]. Formaldehyde exposure and Leukemia:(2009):A New Meta-Analysis and

[27]. Potential Mechanisms, Mutation Research/Reviews in MutationResearch., 681 (2-3); Pp. 150-168.

[28]. Occupational Safety and Health Administration,( 2008): Formaldehyde.

[29]. http://www.osha.gov/SLTC/formaldehyde/index.html retrieved 2009-09-01.

[30]. Formaldehyde, 2-Butoxyethanol and 1-tert-Butoxypropan-2-ol, IA RC. (2006): Monographs on the Evaluation of Carcinogenic Risks to Humans 88, Lyon, France: International Agency for Research on Cancer. I S B N $92-832-1288-6$. P p. $39-$ 325http ://monogra phs.ia rc.fr/ENG/Monogra phs/vol88/mono88-6.pdf. Formaldehyde (gas).

[31]. Francis-Floyd and Ruth. (1996): Use of Formalin to Control Fish Parasites, Institute of Food and Agricultural Sciences, University of Florida, http://edis.ifas.ufl.edu/VM061.

[32]. Franks, S.J. (2005): A mathematical model for the absorption and metabolism of formaldehyde vapour by humans. Toxicology and Applied Pharmacology. 206(3): 309-320.

[33]. Grammer, L.C., Harris, K.E., Shaughnessy, M.A., Sparks, P., Ayars, G.H., Altman, L.C. and Patterson, R. (1990): Clinical and immunologic evaluation of 37 workers exposed to gaseous formaldehyde. J Allergy Clin Immunol 86(2): $177-81$.

[34]. Günther Reuss, Walter Disteldorf, Armin Otto Gamer, Albrecht Hilt., (2002): "Formaldehyde" in Ullmann's Encyclopedia of Industrial Chemistry, Wiley-VCH, Weinheim.doi :10.1002/1 4356007.a1 1_619

[35]. Heck, H., (1990): Formaldehyde Toxicity, New Understanding. Critical Reviews in Toxicology, 20: $397-426$.

[36]. Hofmann, A.W., (1868): Zur Kenntnis des Methylaldehyds. Annals of Chemistry and Pharmacy. Annalen der Chemie und Pharmacie, vol. 145(3). Pp. 357-361.

[37]. IARC Monographs on the Evaluation of Carcinogenic Risks to Humans Volume 88 (2006): Formaldehyde, 2 -Butoxyethanol and 1 tert-Butoxypropan-2-ol, WHO Press, 2006 (English).

[38]. Indoor Air Pollution in California (2005): Air Resources Board, California Environmental Protection Agency. Pp. 6570,http://www.arb.ca.gov/research/indoor/ab1 1 73/rpt0705. pdf.

[39]. Isseibacher, L., (1990): Harrison's Principal of internal medical, $6^{\text {th }}$ Edition, Blakison, New York. Pp1301.

[40]. Johnson, D.R., (2005): Introductory anatomy, respiratory system, 8: 62-63.

[41]. Kamata, E., Nakadate, M., Uchida, O., Ogawa, Y., Suzuki, S., Kaneko, T., Saito, M. and Kurokawa, Y. (1997): Results of a 28- 
month chronicinhalation toxicity study of formaldehyde in male Fisher-344 rats.

[42]. J Toxicol Sci. 22(3): 239-54.

[43]. Kerfoot, E.J. and Mooney, T.F. (1975): Formaldehyde and paraformaldehyde

[44]. study in funeral homes. Am Ind Hyg Assoc J 36(7): 533-537. Koontz, M. (1996): Residential Indoor Air Formaldehyde Testing Program: A Pilot Study,"

[45]. Kulle, T.J., Sauder, L.R., Hebel, J.R., Green, D.J. and Chatham, M.D. (1987): Formaldehyde dose- response in healthy nonsmokers. Japca 37(8): 91 9-924.

[46]. Mangum, Jeffrey G.,Darling Jeremy, Menten, Karl M., Henkel, Christian (2008): Formaldehyde Densitometry of Starburst Galaxies.Astrophys. J. 673 (2): 832-846.

[47]. McGwin,G., Lienert, J., Kennedy, J.I., (2009): Formaldehyde Exposure and Asthma in Children: A Systematic Review. Environmental health perspectives. 118 (3): 313-347

[48]. Mc Laughlin, W.C. (2000): Human Biology and Health, Englewood cliffs, New Jersey, USA, Pp. 40-41.

[49]. No More Toxic Tub: (2009): Getting Contaminants Out Of Children's Bath \& Personal Care Products, Campaign for Safe Cosmetics, http://safecosmetics.org/downloads/NoMoreToxicTub Mar09Report.pdf.

[50]. Occupational Safety and Health Administration (1980): Safety and Health Standards. Washington DC: Occupational Safety and Health Administration, (revised). (29CFR 1910-1000).

[51]. Patel, Alkesh, (2007): Formaldehyde Ban set for 22 September 2007, WebWire, http://www.webwire.com/ViewPressRel.asp?aId=41468.

[52]. Porter, J.A. (1975): Letter: Acute respiratory distress following formalin inhalation. Lancet 2 (5): $603-624$.

[53]. Salem H and Cullumbine H (1960). Inhalation toxicities of some aldehydes. Toxicol Appl Pharmacol 2: $183-7$.

[54]. United States Department of Health and Human Services (2005): Public Health Service. National Toxicology Program. Report on $\mathrm{Ca}$

[55]. Residential Indoor Air Formaldehyde Testing Program: A Pilot Study," M.

[56]. Rusch, G.M., Clary, J.J., Rinehart, W.E. and Bolte, H.F. (1983): A 26-week inhalation toxicity study with formaldehyde in the monkey, rat, and hamster. Toxicol Appl Pharmacol. 68(3): 329-43.

[57]. Singh, I. (2006): Human Histology, $5^{\text {th }}$ Edition, Japee Brothers, New Delhi, Pp. 218-222.

[58]. Sinnatamby, S.C. (1999): Last's Anatomy Regional and applied, $11^{\text {th }}$ Edition, Church Hill Living Stone, Edinburgh London, New York, Pp. 221- 225.

[59]. Solomons, K. and Cochrane, J.W. (1984): Formaldehyde toxicity. Part I. Occupational exposure and a report of 5 cases. S. Afr Med J. 66(3): 101-2.

[60]. Strutts, M.J., Witek, T.J., Jr. and Beck, G.J. (1986): Effects Of Formaldehyde on bronchial Ion transport, 82(2): $360-67$.

[61]. Weast, Robert C. (1981): Handbook of Chemistry and Physics (62nd edj. Boca Raton, FL: CRC Press. ISBN 0-8493-0462-8. Pp. 304.

[62]. Weber-Tschopp, A., Fischer, T. and Grandjean, E. (1977): Irritating effects of formaldehyde on man . Int Arch Occup Environ Health. 39(4): 207-18.

[63]. Woon, David, E. (2002): Modeling Gas-Grain Chemistry with Quantum Chemical Cluster Calculations. I. Heterogeneous Hydrogenation of CO and H2CO on Icy Grain Mantles, Astrophys. J. 569: 541-548.

[64]. Woutersen, R.A., van Garderen-Hoetmer, A., Bruijntjes, J.P., Zwart, A. and Feron, V.J. (1989): Nasal tumours in rats after severe injury to the nasal mucosa and prolonged exposure to $10 \mathrm{ppm}$ formaldehyde. J Appl Toxicol . 9(1): 39-46.

[65]. Wrigth, D.J. (1993): Human Biology and health, Englewood Cliffs, New Jersey, USA, Pp. 280-281.

[66]. Zuckerman, B., Buhl, D., Palmer, P., Snyder, L. E. (1970): Observation of interstellar formaldehyde. Astrophys. J. 160: $485-506$. 